R. Histórla, São Paulo, n. 121, p. 135-140, ago/dez. 1989.

\title{
ASPECTOS DA MARGINALIDADE MEDIEVAL: ALGUMAS ABORDAGENS RECENTES
}

\author{
José Roberto de Almeida Mello \\ Jônatas Batista Neto ${ }^{1}$
}

Esta nota tem por objetivo fornecer aos leitores brasileiros informaçōes sobre o tema acima mencionado tal como ele aparece em alguns artigos recentes, da década de 80 , publicados em periódicos especializados, os quais foram objeto de discussão em seminários organizados pelos professores de História da Civilização Medieval do Departamento de História da Faculdade de Filosofia, Letras e Ciências Humanas da Universidade de São Paulo, no decorrer do segundo semestre de $1986^{2}$.

Dois deles tratam da prostituição em cidades italianas (Veneza e Florença), um terceiro se ocupa da vagabundagem na Ile-de-France, outro versa sobre as relações entre marginalidade e heresia e o último examina o perfil do ladrão no Beowuif e nas sagas islandesas ${ }^{3}$.

A primeira observação que nos cabe fazer diz respeito à natureza das fontes utilizadas pelos autores. Em geral, trata-se de documentação oficial, cobrindo períodos relativamente curtos, analisada de forma exaustiva. Para o estudo da prostituição na Itália, foram usados respectivamente por E. Pavan e R. Trexler,

1 Departamento de História - FFLCH/USP.

2 Além dos autores desta nota, participaram dos seminários os Profs. Drs. Carlos Roberto Figueiredo Nogueira, Ivone Marques Dias, Victor Deodato da Silva, e os estudantes de graduação e de poss-graduaçảo Paulo Eduardo Dias de Mello, Frederick James Roth e José Rivair Macedo.

3 PAVAN, Elisabeth. Police de Moeurs, Societé et Politique à Venise à la Fin du Moyen Âge Revue Historique, p. 536, 1980; TREXLER, Richard C. "La Prostitution à Florence au XV' Siècle" (Annales ESC, 1981, 36,6); COHEN, Esther. "Le Vagabondage à Paris à la Fin du XIVe Siecle" (Le Moyen Âge, v. 88, n. 2, 1982); GEREMEK, Bronislaw. "Hérétiques et Déracinés au Bas Moyen Age (Annales ESC, v. 37, n. 1, 1982); ANDERSON, Theodore. "The Thief in Beowulf" (Speculum, v. 59, n. 3, 1984). 
MELLO, Josk Roberto de Almeida \& BATISTA NETO, Jônatas. Aspectos da marginalidade medieval: algumas abordagens recentes.

a legislação criminal da República de Veneza (séc. XV) e os Registros do Ofício da Onest florentina (1441-1523). A vagabundagem na Ile-de-France pôde ser examinada através do Registro criminal do Châtelet de Paris para os anos 1389-1392. E mesmo um autor voltado para as questóes literárias, como Theodore Anderson, só não utilizou a legislação anglo-saxônica e nórdica por não encontrar nela nenhuma referência substancial ao furto, sendo pois obrigado a recorrer às fartas informaçöes existentes nas sagas islandesas. Apenas o estudo de $\mathrm{B}$. Geremek não menciona qualquer documentação em particular por tratar-se mais de um ensaio do que de pesquisa original.

Embora o objetivo que norteou as pesquisas não tenha sido idêntico, os autores acabaram por esbarrar em questôes que percebemos serem comuns a espaços geográficos diferentes numa mesma época e transcender os curtos limites de tempo impostos pela documentação.

O primeiro problema que se põe é o da definição de marginalidade, que se apresenta, nesses estudos, com várias faces, como, por exemplo, a vagabundagem, a gatunagem, o desenraizamento social e a prostituição.

A vagabundagem é caracterizada por E. Cohen, com base nas teorias do sociólogo francês A. Vexliard, como sendo a condição de "quem pertence a nenhuma categoria social estabelecida". Quanto à sua origem, ela pode ser elementar (decorrente de calamidades, como peste, guerra, fome, etc.) ou estrutural (provocada pela rigidez das estruturas sociais, que excluem os que a ela não se adaptam). Para descobrir em qual delas se encaixa a vagabundagem na Ile-de-France no final do século XIV, é que a autora faz um levantamento das biografias dos acusados, contidas no registro Criminal do Chattelet.

Em geral eles pertenciam às camadas desfavorecidas da população (artesãos, "compagnons", domésticos, criados, trabalhadores agrícolas), quase sempre do sexo masculino, provenientes de Paris e circunvizinhanças.

Ao contrário da explicaçāo tradicional dos historiadores, a Autora não encontrou como explicaçăo para o fenômeno da vagabundagem, a fuga das devastações da guerra $\mathrm{e}$ a propagação da peste. Nos registros do Chatelet, a razão mais frequentemente apresentada seguida dos "motivos econômicos legítimos", como a migração para Paris em busca de trabalho e melhores salários ou deslocamento imposto pela própria natureza de certas profissōes (por ex., a movimentaçẩo sazonal dos trabalhadores agrícolas). A guerra também deu a sua contribuição, na medida em que se constituia numa atividade atraente para muitos indivíduos, sobretudo os mais jovens. Engajados nos exércitos como 
valetes, deslocavam-se eles frequentemente pelas diversas frentes de combate. Testemunho disso é o grande número de soldados mencionados nos registros. Da mesma forma a guerra fez aparecer o nobre vagabundo.

Como conclusão a Autora sugere que a mobilidade social caracterizada como vagabundagem no norte da França tenha sido conseqüência das crises econômicas do século XIV, adotando portanto a posição defendida pelos sociólogos.

$\mathrm{O}$ artigo, apesar de sua clareza, dá margem a algumas dúvidas. Além da já mencionada questão das causas, sobre as quais a própria Autora se pronunciou com evidente cautela, fica ainda pendente a própria definição de vagabundagem, porquanto os arrolados no Registro do Châtelet não o foram exclusivamente por sua condição de vagabundos, mas por terem cometido algum crime. Dessa forma, a amostra que possuimos não serve de base para o conhecimento da amplitude do fenômeno na Ile-de-France.

E afinal o que era vagabundagem? Sobre esta questão, a definição de Vexliard acima mencionada parece não constituir uma resposta cabal, uma vez que a característica comum aos 128 acusados dos Registros do Chatelet, é a mobilidade, seja ela espontânea ou imposta pelas circunstâncias, transitória ou permanente. De qualquer forma, essa rejeição definitiva dos quadros da sociedade que é o ingrediente essencial da definição do sociólogo francês não se verifica para uma boa parte dos casos estudados. Disso a própria Autora parece ter tido consciência ao afirmar que o século XIV provocou o aparecimento de uma variada gama de fenômenos, que se pode considerar ou não como vagabundagem.

Se a vagabundagem em Paris não pode ser inteiramente assimilada à marginalidade, na Islândia do século XII, esta era o ingrediente fundamental no delineamento da figura de um tipo especial de ladrão, conhecido no Brasil como gatuno.

Roubando furtivamente, na calada da noite, o gatuno opõe-se ao assaltante que, de forma violenta ou não, mas às claras, expropria a vítima.

Gatuno é o termo que Theodore Anderson propõe para preencher uma lacuna do manuscrito do Beowulf, poema épico anglo-saxônico do século VHI. Trata-se de uma passagem de interpretação controvertida, onde a escolha do termo apropriado tem uma importância crucial. Estudiosos da obra haviam sugerido a leitura "nobre" ou "escravo" para o trecho rasurado do texto. Discordando dessa interpretação, Theodore Anderson prefere o substantivo 
MELLO, José Roberto de Almeida \& BATISTA NETO, Jônatas. Aspectos da marginalidade medieval: algumas abordagens recentes.

gatuno (thief). Esse portanto, o objetivo básico do seu artigo. A pesquisa das sagas islandesas constitui af apenas o meio encontrado para argumentar em favor de sua opção.

Tendo buscado, sem sucesso, exemplos da legislação anglo-saxônica e nórdica, que pudessem esclarecer a posição do ladrão no Beowulf, viu-se constrangido a recorrer às sagas islandesas, onde tais casos são abundantes.

Daí advem o interesse para nós dos resultados da investigação. Ela nos mostra justamente o caráter marginal do gatuno naquela sociedade. $O$ tipo de roubo que praticava, por seu caráter furtivo e secreto, era considerado extremamente vil e aos indivíduos que o praticavam, aplicavam-se várias qualificações pejorativas, que nos mostram a similaridade de sua situação com aspectos da marginalidade levantados pelos autores dos demais artigos estudados.

O gatuno é associado inicialmente ao forasteiro, ao indivíduo sem eira nem beira, sem lar, sem família, sem vínculos com a terra, em suma, um pária. Somam-se a isso as conotações de efeminação e de bruxaria, encontrados em muitos dos relatos das sagas. Além do mais, ele é quase sempre de baixa extração social, pois o furto, ao contrário do assalto, é considerado impróprio do homem livre ou do nobre.

Aqui temos assim, novamente, o encontro da marginalidade com a criminalidade, uma criminalidade especial, é verdade, considerada mais pela falha de caráter que revela do que por seu efeito prático mas, por isso mesmo, capaz de colocar o indivíduo à margem da sociedade, tornando-o um desajustado nos moldes da definição de $\mathrm{A}$. Vexliard.

$\mathrm{Na}$ definição do gatuno pela sociedade islandesa, encontramos portanto um elemento sexual, a alusão a um desvio de comportamento. Tal aspecto é o objeto dos estudos de Elisabeth Pavan e Richard Trexler sobre as cidades de Veneza e Florença no século XV. Aí encontramos, com certas variantes, aqueles aspectos já citados da marginalidade, ou seja a mobilidade, a criminalidade e o comportamento sexual heterodoxo.

Mobilidade. Quem mais se preocupa com ela é Trexler, ao estudar demograficamente a prostituição em Florença, tanto no que diz respeito ao recrutamento das mulheres pelo serviço da Onestà (organizado em 1403), quanto com relação aos frequentadores dos bordéis. Nota o pesquisador americano que em geral não são originários de Florença, vindos quer de outras áreas da Itália, quer das regiões transalpinas, como a Alemanha e os Países-Baixos. 
Conquanto o levantamento demográfico não seja o objetivo central de Elisabeth Pavan, não deixa ela de notar a presença de um número considerável de estrangeiros em Veneza. Fala mesmo da existência de verdadeiras redes aumentando o florescente comércio prostitucional veneziano de prostituição.

C'riminalidade - Não que as prostitutas fossem propriamente criminosas, embora frequentemente cometessem pequenos delitos. Ocorria, no entanto, que bastava a sua presença para que desordens eclodissem nas imediações dos prostíbulos. Mais ainda, em Veneza, elas eram muitas vezes responsáveis pela sonegação de impostos decorrentes do contrabando de vinho.

Comportamento sexual heterodoxo - A prostituição feminina não era considerada crime pela sociedade ou pelas autoridades, sendo até protegida pelo governo das duas repúblicas. A sodomia é que foi objeto de condenação e de perseguição.

Em ambas as cidades, a prostituição feminina estava intimamente relacionada com a perversão sexual, na medida em que foi estimulada pelo estado para coibir a difundida prática da sodomia. Nesse sentido, ela foi tolerada, protegida e organizada, quase perdendo o seu caráter marginal. Tal não aconteceu com o homossexualismo, que foi objeto de uma crescente repressão, especialmente em Veneza, onde o Conselho dos Dez, órgão de governo da República, chegou a criar uma comissão especial destinada a cuidar do problema, com poderes para prender, torturar e executar os culpados desse vício.

Dessa forma, na medida em que a prostituição feminina teve uma função social positiva nas duas cidades, não a podemos considerar propriamente marginal. A sodomia sim, porque considerada ofensiva a Deus e potencialmente perigosa para a segurança da cidade, tendo em vista o precedente de Sodoma e Gomorra amiúde citado pelas autoridades civis e eclesiáticas em seus pronunciamentos. Ela foi marginalizada com maior ou menor intensidade tanto em Florença quanto em Veneza, onde a repressão se tornou muito violenta no final do século XV.

O temor da sodomia foi a causa do estímulo à prostituição feminina, considerada como um antídoto a essa prática. Porém favorecer a prostituição tinha também os seus inconvenientes, tais como as algazarras, os escândalos, o mau-exemplo, a possibilidade de contaminação da população local e o estado viu-se obrigado a tomar providências para, pelo menos, circunscrever essa atividade a uma área da cidade. Foram criadas comissões como o Ofício da Onestà em Florença, órgão para o policiamento e solução de querelas surgidas 
MELLO, José Roberto de Almeida \& BATISTA NETO, Jônatas. Aspectos da marginalidade medieval: algumas abordagens recentes.

nesse meio e providenciaram-se instalações para abrigar as prostitutas, como o famoso Castelleto de Veneza.

$\mathrm{O}$ aspecto mobilidade, que aparece no caso da prostituição italiana bem como dos fenômenos de marginalidade anteriormente expostos, também surge no estudo de B. Geremek associado à propagação das heresias. Trata-se portanto de uma abordagem que relaciona o desenraizamento social à história das idéias.

O historiador polonês ressalta a importância das vias de comunicação para a circulaçáo do pensamento heterodoxo. Acredita que o homem que rompeu com as suas amarras sociais de origem se tornava mais aberto à recepção de idéias heréticas. É nas estradas e nos pontos de parada, tais como tavernas, forjas, moinhos, etc., que vamos reencontrar os vagantes mencionados por E. Cohen, revestidos agora de uma nova função, a de transmissores de concepções religiosas divergentes.

Como vemos, mau grado as diferenças regionais e cronológicas, o fenômeno marginalidade conserva certas características comuns. Primeiramente a mobilidade, momentânea ou permanente, já que mesmo aqueles elementos aparentemente mais estáveis, enquadrados e protegidos pelas cidades italianas, como as prostitutas, não permaneciam muito tempo num determinado local, como testemunham os registros municipais.

Depois, a exclusão dos quadros sociais, da qual o exemplo mais gritante talvez seja o do gatuno das sagas islandesas, tendo em contrapartida a aceitação temporária no caso das prostitutas de Florença e de Veneza.

Finalmente a origem social é mais ou menos comum, no sentido de que se tratam de pessoas humildes.

Sendo um tema de pesquisa de interesse relativamente recente, é natural que a marginalidade ofereça ainda um vasto campo de investigaçăo pela frente. Assim seria desejável, por exemplo, que estudos como os de E. Pavan e R. Trexler se estendam a outras comunidades urbanas da Idade Média. 